\title{
Políticas del cuerpo y subjetividades fronterizas en el libro Shumpall de Roxana Miranda Rupailaf
}

\section{Body politics and border subjectivities in the book Shumpall of Roxana Miranda Rupailaf.}

\author{
Fernanda Moraga-García \\ Universidad Católica Silva Henríquez \\ moraga.fer@gmail.com
}

\begin{abstract}
SÍNTESIS
El presente artículo tiene por objetivo explorar, desde una perspectiva de género, las diferentes posiciones de sujeto en el libro Shumpall (2011) de Roxana Miranda Rupailaf. Las posibilidades que el texto de la poeta presenta al respecto, fundamentalmente, están relacionadas con la disolución de jerarquías preexistentes que sostienen una conformación unívoca en la representación del sujeto "mujer" a partir de las percepciones mapuche y no mapuche. Por lo tanto, lo que se desea rastrear es cuáles son aquellas rupturas que la poeta realiza a partir de la resignificación del relato oral mapuche, en el epew (relato oral de tipo ficticio) de shumpall. Las rupturas se articulan con la autoproducción de subjetividades fronterizas y con la configuración política del cuerpo mestizado, dentro de un contexto de experiencias de cruces culturales.
\end{abstract}

\begin{abstract}
This article aims to explore, from a gender perspective, the different subject's positions in Shumpall (2011) by Roxana Miranda Rupailaf. The posibilities that the text of the poet represent, are related fundamentally to the dissolution of preexisting hierarchies that hold a unique conformation in the representation of the subject "woman" from the mapuche and non-mapuche perceptions. Therefore, what is necessary to track is, what are those made by the poet from the resignification of the mapuche oral narration, in the epew (oral account of fictitious type) of shumpall. Ruptures are articulated with the self-production of border subjectivities and the political configuration of the body mestizado, within a context of experiences of cultural crossings.
\end{abstract}

Palabras claves: Roxana Miranda Rupailaf, mapuche, subjetividad fronteriza, poesía, shumpall

Key words: Roxana Miranda Rupailaf, mapuche, border subjectivity, poetry, shumpall. 


\section{Comentarios introductorios}

El tercer libro publicado de Roxana Miranda corresponde a Shumpall $(2011)^{1}$. En él la poeta da cierta continuidad a su poemario anterior Pu llimeñ ñi rulpázuamelkaken / seducción de los venenos (2008), fundamentalmente, a partir de una relectura de la narración oral mapuche que lleva el mismo nombre del texto que ahora nos interesa (shumpall). Es decir, entre ambas producciones poéticas se desenvuelve un puente que se inicia en el relato de Kai Kai y Tren Tren para desembocar en la resignificación del epew que cuenta la historia de Shumpall. La autora plasma ciertos cruces -por cierto inevitables, dada la articulación que ambas narraciones sostienen dentro de la tradición oral mapuche-, entre las sierpes del agua y de la tierra y las transformaciones de la voz enunciativa que emerge en Shumpall.

Antes de adentrarnos en la reflexión sobre el poemario que citamos, es necesario mencionar que el epew que narra la historia de shumpall, en términos generales, es el siguiente:

Una hermosa joven mapuche fue al mar, río o lago, a recoger marisco, lavar, bañarse, mirarse en el agua; un shumpall, directamente en su apariencia de sireno o indirectamente en forma de ola o remolino, arrebata a la niña y la lleva hacia el centro de las aguas o hacia la profundidad de éstas; allí se casa con ella, y la joven desaparece de las cercanías; sus padres, sobre todo la madre, quedan solos y tristes por la desaparición de su hija, lloran y esperan o la buscan, rezando y haciendo machitun para encontrarla; después de un tiempo, los padres sueñan con la joven, o ésta los va a visitar, por su voluntad o enviada por Shumpall, sola o acompañada de su pequeño hijo, (el que a veces, al ser destapado el canasto en que va, se convierte en agua, o se observa su apariencia de "lobito

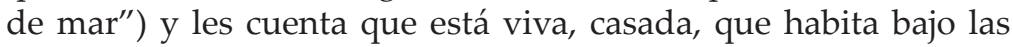
aguas y que no la busquen más. Luego, la joven pide a sus padres y otras personas de la comunidad que vayan a la playa, donde se efectuará el pago por el matrimonio; los padres y la comunidad llevan los elementos necesarios y organizan la fiesta ritual; entonces, Shumpall viene en forma directa (en su apariencia de sireno o de lobo de mar), o figurada (ola, marea, viento, temporal), llena la playa de pescado, otros bienes del mar o dones para pescar; con esto, todos quedan satisfechos y felices, por los bienes o dones recibidos y por la relación establecida con el esposo de la joven, y 
ésta, sola o acompañada por Shumpall, se va también feliz hacia su morada en las aguas (Carrasco 25).

Recogemos entonces, que la articulación existente entre el shumpall que nos entrega Roxana Miranda y el relato de origen, está sustentada en la relación amorosa entre la mujer y Shumpall y el hijo de ambos. Sin embargo, esta bisagra intertextual nos proporciona un relato de origen intervenido ya que, primero, existe una apropiación y resignificación del mismo en el libro de la autora, y segundo, hay una problematización respecto a la relación de equilibrio (dualidad) entre los amantes y el hijo.

Aunque el texto de Miranda está compuesto por estos tres elementos amorosos que al mismo tiempo aparecen fusionados en dos, se rompe la armonía porque finalmente los personajes no pueden acceder al encuentro amoroso del equilibrio. En el relato tradicional, esta unión de elementos se manifiesta a través de una cierta "felicidad" otorgada por un "para siempre". Además, debemos considerar que las voces enunciativas de la poeta emergen siempre en un territorio corporal ambiguo, de cruce dialógico con otros relatos orales mapuche que subyacen a través de la historia de este particular shumpall que nos entrega la poeta. En este sentido entonces, estamos frente a una relectura del relato original de Shumpall, la que apela a la compleja construcción de una "singularidad" que se rearma en un contradictorio devenir de cortes y continuidades en la experiencia.

El texto se compone de cuatro partes entretejidas a modo de una espiral. La primera parte llamada "Primer oleaje. De la invocación", está compuesta por ocho poemas, los que -de igual forma que en el resto del texto-, solo aparecen denominados en orden correlativo, por números. La siguiente parte, "Segundo oleaje. Delirios de la sal", también consta de ocho poemas. A esta última, le sigue "Tercer oleaje I. Del abrazo y los descensos" que contiene seis poemas, para finalizar con “Tercer oleaje II. De la desaparición”, el que solo está conformado por tres poemas. Es importante mencionar que el libro se abre con una antesala de dos poemas breves que dejan entrever un origen reinaugurado del relato de Shumpall, a la vez que señala la huella inicial de todas las transformaciones en la posición enunciativa del sujeto: 
$Y$ resultó que eran cientos

Que en el agua flotaban heridos por la luz

En delirio cantaban una melodía parecida al llanto de la muerte (Miranda 2011, 7)

Fue entonces que decidí arrojarme

A un océano que se atoraba de visiones (Miranda 2011,9)

Para comenzar con la exploración de este texto, es necesario remontarse a $P u$ llimeñ ñi rulpázuamekaken. Seducción de los venenos (2008), puesto que el implícito puente de cruce que la autora traza entre uno y otro libro, se abre en la narración de las sierpes. Precisamente, en este último poemario mencionado, nos encontramos con un espacio escritural en el cual los territorios de la frontera no marcan ningún límite, y menos, perfilan un espacio concluyente. Por lo tanto, el texto nos hace comprender una materialización de la frontera como un tejido de interacciones, dentro del cual una de las pulsiones cardinales se hace presente a través de la interrelación dialógica entre las diferentes representaciones del cuerpo de la serpiente, de las mujeres y de la sujeto de los poemas. Visto de esta manera, la narración de origen que apela a la tensión entre las aguas y la tierra, genera un nuevo espacio de vinculaciones y de representaciones que vienen a pluralizar aún más la construcción fronteriza de las subjetividades que exploramos. Es así como el discurso poético del texto sobrepasa la escritura de "un solo libro" ${ }^{2}$, para adentrarse en una zona mestizada, en la cual entran en juego diferentes planos simbólicos de la experiencia y de la subjetividad. Es aquí donde explosiona el desplazamiento de lo definitivo y por lo tanto, la metáfora de una sujeto mestizada, porque emerge, frente a cualquier conjunto discursivo jerárquicamente organizado, un espacio heterogéneo. El puente de cruces que nos tiende la poeta, nos aproxima a la presencia de sujetos escriturales que no existen en el vacío porque no pueden emplazarse de modo aislado, sino que existen y experiencian dentro de una trama de relaciones que configuran corpográficas que son irreductibles unas a otras y totalmente imposibles de superponer. Se trata entonces, de un intersticio textual donde opera un orden que, pensando en Foucault, podríamos llamar heterotópico en cuanto corresponde a una plataforma heterogénea de lugares -cuerpos y textos- de transferencia. Por lo tanto, el puente de reunión y de 
cruce que se tiende entre ambos poemarios, se abre a partir de la continuidad resignificada entre los relatos orales. Fundamental es hacer mención a que, efectivamente, como afirma Paulo Huirimilla, Pu llimeñ ñi rulpázuamelkaken / Seducción de los venenos, finaliza con una alusión a la figura de una mujer-pez (Huirimilla 2009, s/p), a lo que podríamos sumar que también se trataría de una apertura, porque La mujer-pez es la que se configura como eje enunciativo en Shumpall:

\author{
y son algas \\ mi cuerpo alga \\ verde blanco que me encuentra \\ mi ojo de agua que me encuentra \\ cantos me salen cantos \\ y una espuma \\ [...] (Miranda 2011, 22)
}

Miro mi cuerpo en los espejos

Shumpall de Miranda nace como narración a partir de la catástrofe producida por las fuerzas vitales de la tierra y el agua. Además, la propuesta de una política de la erótica se prolonga entrelazada a la experiencia de la voz enunciativa, desde una perspectiva que ya no se basa en una búsqueda y creación del espacio erótico, si no que más bien, aparece como un lugar ya apropiado en la experiencia del sujeto de los poemas. El puente tendido entre ambos textos, viene a configurarse como un lugar de flujo creativo de confluencias en el cual se filtran y se mezclan puntos de vista o localizaciones diferentes y múltiples. A fin de cuentas, se posiciona como parte del territorio fronterizo que cruza toda la escritura de Roxana Miranda.

A partir de este enclave texto a texto, coincido con Roxana Miranda cuando afirma que en su libro Shumpall -aunque ya lo hace en el poemario anterior- despliega un territorio de la ambigüedad (Miranda en Arellano s/p). El espacio escritural del texto se abre fuera de cualquier depósito de lo preciso o de lo exacto, puesto que la emergencia de "figuras latentes" se construye como apertura textual a partir de la representación de la persistente transformación del sujeto, como ya se mencionó anteriormente. A través de la ambigüedad de los cuerpos, Roxana Miranda emplaza un "tercer espa$\mathrm{cio}^{\prime \prime}$ donde las relaciones intersubjetivas aparecen problematizadas 
debido a que la experiencia básica, podemos decir, es el desgaste del fundamento binario masculino/femenino, es decir, se disuelve la jerarquía. Podríamos hablar de "deslizamientos" que se van originando en las diferentes dimensiones de las enunciaciones, tendiendo éstas a "amasarse", a fusionarse unas con otras en un empalme de trayectos de fuga, de roturas, encargadas de liberar este "tercer espacio". Territorio intersticial donde los diversos discursos se van "hibridando" unos con y en otros, desmoronando la representación de "lo uno", es decir, la representación indisoluble de la tradición oficial.

\section{Políticas y mestizadas de la subjetividad}

El discurso poético del libro, se realiza a través de la construcción de cierta rugosidad en la voz enunciativa. Surgen las voces de un "yo", de un "tú" y de un "él", las que se intercambian y comparten el lugar de enunciación de cada uno: "Ya te digo que es contigo/ que soy yo/ que estás en mí" (Miranda 2011, 18).

Aunque, por una parte, se posiciona una voz enunciativa que atraviesa todo el libro orientando la dirección del discurso poético y por otra parte, emerge otra voz implícita que es apelada y materializada por la anterior; el texto se despliega a través de una polifonía de voces que confecciona el escenario fundamental del libro. Este emplazamiento intencional en el texto permite, desde su inicio, la escenificación de un discurso complejo y socializado en el cual, mientras se pluraliza el habla de uno y otro personaje, al mismo tiempo se construyen como el mismo personaje, es decir, el "yo" enunciativo se va multiplicando a través de las posibilidades que el mismo "yo" va abriendo en la autoproducción de subjetividad. Desde este ángulo en la construcción del texto, podemos decir que esta política discursiva que utiliza la poeta, sitúa los diferentes puntos de vista o posiciones posibles que sobre la "realidad" construyen las voces enunciativas. De modo que es a través de la comunicación polifónica y multivocal y por lo tanto, por medio de las diferentes posiciones de sujeto, donde el significado o la resignificación de la experiencia se asume como una práctica de la subjetividad de significar la interrelación de sujetos y su consecuencia, la ambigüedad. Este emplazamiento escritural consigue que el significado de cada voz, tal 
como lo plantea Bajtín (1986) en su propuesta del “diálogo interno de la palabra", sea orientado hacia una respuesta:

De esta orilla, conozco los gritos.

los desgarros de las algas que se avientan desde el fondo como si de un abrazo explotaran las vísceras y el cuerpo se esparciera por el agua (Miranda 2011, 16).

La "invocación" al sujeto de las aguas, Shumpall, que la voz enunciativa realiza en esta primera parte del libro, se distiende entre las aproximaciones corporales y las implicancias que desprenden las entradas de un sujeto en otro, como ya señalamos: "Voy a hundirme en esta ola que es tu nombre" (Miranda 2011, 11). Es notable, como de aquí en adelante la ambigüedad en la enunciación marca el tono permanente de los poemas. Se trata de "casi" la imposibilidad de reconocer cuál de los sujetos habla. Digo "casi", porque la poeta al parecer, no olvida que detrás o delante de su texto hay lectores y lectoras que, aunque sea de manera implícita, registrarán, por lo menos, la convergencia de un/a yo y un/a Shumpall. Sin duda, la escritura a la que accedemos en este libro se posiciona -y nos posiciona- en una dimensión textual que parte de la interrelación como signo cardinal de la experiencia. Por lo tanto, los poemas entronizan una subjetividad que como tal, no puede realizarse como una organización taxativa, como un eje invariable y soberano. Esto faculta la posibilidad de no pensar las relaciones de una forma lineal y vertical, lo que, por supuesto, pone de manifiesto tanto las contradicciones, como las réplicas constitutivas de la experiencia, abriendo el acceso a un espacio de conocimiento representado por creaciones rizomáticas, en las cuales, por una parte, el/la sujeto poético se construye en la medida que interactúa con "otro" y por "otro", pudiendo reconocerse en ambos:

Te amo con ese coro de ninfas que te canta espejos en los cuales peinas tus cabellos

Con ellas tú entras en mis aguas

Son las ninfas que salas con tu cuerpo. 
Me sumerjo en una y huele a ti.

La voy amando por contener tus líquidos.

Lamiendo estoy a esta mi doble tanteando el calor de la mano que le anduvo.

(Miranda 2011, 17)

Si realizamos una travesía de principio a fin por el libro, nos encontramos que el texto tiene como foco la narración de una "visión" delirante de las huellas de una relación amorosa. Este presagio alucinado que manifiesta la sujeto de los poemas, se mueve dentro del juego de una erótica de los cuerpos, desplegando espacios como el cruce de relatos orales, el incesto y la vulneración del binarismo femenino/masculino. Por lo tanto, hallamos aquí un desenvolvimiento implícito de una política de las sexualidades que finalmente desemboca en la muerte, la que en definitiva origina la visión de la sujeto, es decir, la apertura del libro. En relación a esto último, es preciso mencionar que la articulación que se realiza respecto al espacio de la muerte como el inicio de una enrevesada visión, surge a propósito de que la sujeto decide quitarse la vista, justamente, para no ser testigo de la muerte de su niño-amante:

entre mis brazos

el niño pez corona de lagas.

Y ya sin él me fui rompiendo

las pieles y la carne a cuchillazos

Voy a morirme de ti, le dije.

Y sólo por no verte

clavé rocas, espinas y conchas a mis ojos.

Ya ciega del mundo, de ti, del mundo, de ti.

No dejaron de venirme en oleaje las visiones.

(Miranda 2011, 44) 
Shumpall es un texto que abre su discurso en la continuidad -quebrada por la muerte-, la que, podríamos decir, se dibuja como una espiral, puesto que se moviliza hacia atrás, hacia delante y hacia dentro. Me refiero aquí, a un desplazamiento múltiple donde se plasma la interrelación entre lo "extra" y lo intratextual. Lo "extra" textual en este sentido, estaría dado por la inmediatez en que se sitúa el libro anterior de la poeta, Pu llimeñ ñi rulpázuamelkaken / Seducción de los venenos, y el puente de cruce entre ambos poemarios respecto a los relatos orales y a la imagen de la mujer-pez. La marcha hacia delante de esta continuidad discursiva, es, sin duda, el avanzar de la historia poética, que a la vez, se inicia en el final de la misma, he aquí el desplazamiento hacia dentro, porque la hendidura de la muerte, será siempre en el texto, la visión de la sujeto. Si retomamos los dos últimos versos del libro Pu llimeñ ñi... citado más arriba: “Ya ciega del mundo, de ti, del mundo, de ti./ No dejaron de venirme las visones" (Miranda2008, 44) y los aproximamos a los tres primeros versos con los que se inicia el poemario Shumpall: "Y resultó que eran cientos/ que en el agua flotaban heridos por la luz/ en delirio cantaban una melodía parecida al llanto de la muerte" (Miranda 2011, 7); reconocemos una complicidad de prolongación ("intratextual") de la misma escritura que se enfatiza en la conexión " $Y$ ". Se trata de una continuidad que establece relaciones hacia fuera y hacia dentro, por lo tanto, estamos frente a la puesta en escena de un proceso de experiencia que diseña las interacciones necesarias en la construcción de una "singularidad" textual y enunciativa. Es necesario señalar aquí, que el proceso de la escritura poética de Roxana Miranda, desde su primer libro, Las tentaciones de Eva, hasta el poemario que exploramos ahora, ha realizado un recorrido que va desde una perspectiva poética distanciada de tradiciones propiamente mapuche, hasta indagar en relatos de la tradición oral, fundamentalmente de la sociedad huilliche. En el segundo libro de la autora ya vemos como el epew de Tren Tren y Kai Kai emerge resignificado o problematizado desde una mirada de reivindicación del cuerpo erótico, entre otros niveles de significación poética. Más aún, este relato aparece fusionado con la gran odisea mítica de origen cristiano. Al respecto, podemos decir por una parte, que el epew que narra la lucha entre los poderes de la tierra y el agua y que aparece en el libro mencionado, se liga al relato que atraviesa a toda la sociedad mapuche, para hacerse más particu- 
lar hacia el final del texto con la mención a la figura de la mujer-pez, la que es de origen huilliche-chilote. Y por otra parte, la prolongación de este epew de fuerzas terrestres y marinas en el libro Shumpall, se transforma, puesto que alude a un imaginario huilliche propio de la isla de Chiloé. En consecuencia y como parte de un proceso de configuración identitaria de las sujetos de los libros, el que apela a una diferenciación, al mismo tiempo que a una identificación cultural; se puede decir al respecto, que la escritura de Roxana Miranda se inscribiría dentro de lo que Mabel García denomina "retradicionalización cultural":

El mito como parte del proceso de retradicionalización del arte mapuche actual, es un dispositivo epistémico a través del cual transitan múltiples significados y sentidos; es, por lo tanto, un lenguaje complejo que puede describirse como una matriz simbólica en la cual se desplazan y actualizan elementos y categorías fundamentales del saber cultural tradicional y ancestral (García 49)

La propuesta poética de Miranda Rupailaf no termina de completarse, porque no es su intención la configuración de un espacio escritural cerrado y unívoco, sino que por el contrario, estamos frente a la exploración de una producción intelectual estética y por intencionada consecuencia, política, que permea todas las lógicas maniqueas y por ende, las posiciones concretas y estabilizadas que operan desde el campo de dominio. Las diferentes posibilidades de resimbolización que ofrece el texto que nos ocupa, no intenta una complacencia con la falta de cualquier centro aglutinador, sino que es justamente la facultad de articular la pluralidad de ejes que confluyen en la voz enunciativa como "centro de operaciones", la que nos invita a seguir el rastro de experiencias que anteceden a la posición de sujeto que el texto nos entrega. Por esta razón, es que su lectura nos aproxima a diferentes dimensiones o niveles de su escritura, las que desenvuelven procesos de aproximación entre un texto y otro, entre una sujeto y otra, y también, el mismo proceso de retradicionalización mencionado antes.

Estamos frente a dimensiones de la escritura que a su vez, corresponden a una toma de posiciones respecto a la percepción del mundo, y que demandan necesariamente y como ya se anotó, una "singularidad". Una particularidad que se hace presente en la con- 
ciencia que la sujeto tiene de sí, puesto que su propia concepción de sujeto ambigua le exige revisar las instrumentos de los que dispone para llevar a cabo el parto (creación) de sí misma, representado en el deseado cuerpo del niño-pez y tejer el vital vínculo social-amoroso entre ella y su amante-hijo. Herramientas que sondean en la emergencia de narrativas de la experiencia para crear territorios de identificación y de configuración diferenciales y la conformación de tejidos de subjetividad intencionados.

Considerar entonces que Shumpall es, en cierto modo, una posibilidad en la prolongación de la experiencia de las sujetos que se cruzan entre el libro anterior y éste, nos despliega una perspectiva fronteriza respecto a la autoproducción de subjetividad. Es decir, la resuelta localización de sujeto que nos plantea la autora se configura en la intercomunicativa de diferentes dimensiones que convergen en su toma de posición del cuerpo como espacio de sexualidades, ritualidades y producciones críticas de la experiencia.

Ya sabemos que el texto se ha inaugurado en una apertura mixta, pues recordemos que al mismo tiempo, la autora está desplegando su escritura a partir del final del mismo. "No dejaron de venirme en oleaje las visiones" (Miranda 2011,44), enuncia la sujeto en el último verso del libro para llevar la imagen hacia el poema que lo abre y que ya se señaló más arriba: "Y resultó que eran cientos/ que en el agua flotaban heridos por la luz/ en delirio cantaban una melodía parecida al llanto de la muerte" (Miranda 2011. 7). En estos momentos es cuando interviene la sujeto -la shumpall- en primera persona lanzándose al agua turbulenta que ha dejado Kai Kai, agua que representa una particular visión del relato de Shumpall. Corresponde a la apropiación, resignificación y problematización que la autora realiza de la narración original y de la cual hablábamos al comienzo de esta lectura, incluyendo sus posibles transformaciones en el tiempo. El que la protagonista se arroje a las agitadas aguas que ha dejado la sierpe, manifiesta la intención de la sujeto de ser protagonista de su propio relato, a la vez que también coincide con su deseo de entrar en su propia experiencia mapuche: "Fue entonces cuando decido arrojarme / a un océano que se atoraba de visiones" (Miranda 2011, 9). De este modo, la sujeto se inicia en el proceso de "invocación" a shumpall simbolizado en el niño-pez: 
Repito este mi rezo

por si vienes.

Aquí, frente a las olas

me arrodillo.

Invoco tus cabellos

anudados por la sal.

Espero a que aparezcas

en la tercera ola niño-pez.

Que me trague el mar.

Que me lleven desnuda por la espuma.

(Miranda 2011, 19)

Se trata del despliegue de una conciencia erótica que se va posicionando en la medida que la sujeto, ya convertida en shumpall debido a su arrojo a las violentas aguas de la serpiente Kai Kai, exhorta en el "primer oleaje" la venida del niño-pez. Este discurso de Roxana Miranda, corresponde a la producción heterogénea de espacios y tiempos dentro de los cuales aparece una voz obsesiva y delirante por el cuerpo del hijo-amante y al mismo tiempo, del cuerpo doliente de la shumpall por la latencia de un desencuentro. Elementos discursivos que se transforman en la materia de la narración poética. La sujeto de los poemas como heterotopia del discurso, siempre está abriéndose a la movilidad del doble, del uno dentro del otro: "Lamiendo estoy a esta mi doble/ tanteando el calor de la mano que le anduvo" (17). Pliegue y transformación que atraviesa todo el poemario. La sujeto es la shumpall que contiene dentro de sí no solo al niño-pez, sino que también es la figura de otros relatos orales:

Miro mi cuerpo en los espejos

y son algas

mi cuerpo alga

verde blanco que me encuentra

mi ojo de agua que me encuentra

canto me salen cantos y una espuma

flores yo tengo flores en abismo

un jardín que es un delirio 
un atavío de pieles peces que me lamen

Mi cuerpo alga en los espejos se repite

Se multiplica

Un mapa de mi hay un mapa de mí

sobre el agua

me confundo

me toco y no soy yo esta agua

esta sal que se deshace.

(Miranda 2011, 22)

La aparición del cuerpo erótico de la "Pincoya" se emplaza por cierto, dentro de la conformación del texto como territorio plural y de disolución de límites, incluso entre los mismos cuerpos. Sin embargo, su presencia como dimensión política dentro de un tejido de parentesco con la shumpall, favorece la transgresión a la prohibición impuesta, a través del incesto con el hijo-pez. Las imágenes entreveradas entre la shumpall y la "Pincoya" potencian la posibilidad de armar otra filiación que busca otras formas de relatar un mestizaje, quebrando lógicas "cosmovisionistas" que apuestan por un retorno ahistórico a ciertas concepciones fundamentalistas de la conformación cultural del pueblo mapuche ${ }^{7}$. La contravención del incesto por la protagonista y su amante, su hijo shumpall (niño-pez), como relato inaugural de un mestizaje "singular" fractura por una parte, el patrón familiar de la tetralogía original llamada Futa Newen (La gran fuerza) y que corresponde a la familia originaria: Anciano (Fucha), Anciana (Kushe), Hombre Joven (Weche Wentru) y Mujer Joven (Ülcha Domo) (Moraga 2006) ${ }^{8}$. Por otra parte, quiebra el patrón de los géneros mediante la dislocación que entregan las imágenes ambiguas de los cuerpos y las sexualidades, a través de la revuelta de los roles y de las identidades predeterminadas culturalmente. Al respecto, tal es el estado de las alteraciones propuestas en el poemario. Por un lado, el encuentro en el parimiento: "Él vino hacia mí/ en la tercera ola./ Vestido de flores marinas/ que navegan el vientre de la madre./ Pez de plata me trajo entre las manos./ Fue ofrenda la trizadura que hicimos en el vientre" (Miranda 2011, 12). "Para él abro este mar" (Miranda 2011, 13). Por otro lado, la erótica del incesto:

Te amo con este coro de ninfas que te canta espejos en los cuales peinas tus cabellos 
Con ellas tú entras en mis aguas

Son las ninfas que salas con tu cuerpo.

Me sumerjo en una y huele a ti.

La voy amando por contener tus líquidos.

Lamiendo estoy a esta mi doble tanteando el calor de la mano que le anduvo.

Todo lo tuyo quiero amarlo.

Océano insaciable de gemidos.

(Miranda 2011, 17)

Si atendemos a la imagen de shumpall dentro del relato mapuche, nos encontramos ya con una simbólica de la ambigüedad, puesto que es una figura que se caracteriza por su largo y hermoso cabello color oro 9 , la que además puede tomar el lugar de mujer y/o de hombre. Aspecto no menor en la simbólica que Roxana Miranda rescata, en relación a la construcción de un escenario poético que apela a una política de las sexualidades en cuanto a sexualidades no normativas. Por lo tanto, la contravención que propone el texto, desmonta la heteronormatividad al mismo tiempo que la concepción de la sexualidad como impulso natural que preexiste de antemano al orden social, a modo de una fuerza inalterable, fuera de lo social y ahistórica $(\text { Rubin } 130)^{10}$. En esta misma línea de atención, el texto emplaza una reflexión respecto a que existen experiencias del amor que están prohibidas o censuradas dentro de la legitimidad de las culturas, por lo que, tanto la homosexualidad como el incesto, corresponderían a dichas prácticas amatorias "abyectas".

En Shumpall la vinculación de los cuerpos se construye como un agente simbólico, cultural y también social que contiene todas las pulsiones dentro de las que se encuentra la ambigüedad genéricosexual y el incesto como problematización de la norma. De este modo, las relaciones entre los personajes, fundamentalmente entre la shumpall y el niño-pez, se manifiestan como un tejido de inestabi- 
lidades. El estado de inestabilidad, incluso es llevado al quiebre del equilibrio que los supuestos cosmovisionales del pensamiento mapuche fundamentan a través de la dualidad. De este modo, la vinculación de los cuerpos recién planteada, es también, inevitablemente, el inicio del desencuentro entre los amantes. Si nos detenemos, por un momento, en la representación del deseo como configuración fundamental de la experiencia de la voz enunciativa, vemos como la ambigüedad se vuelve a desplegar a partir de una perspectiva contradictoria en esta experiencia del deseo. Se trata de una forma de concebir el cuerpo como un territorio creado por múltiples fuerzas y formando parte, a la vez, de múltiples fuerzas (Butler 2006). Es así como, dentro del juego temporal que está presente en el texto, la sujeto nos anticipa en la primera parte, que Shumpall -el niño pezvendrá por ella en la "tercera ola"11 frente a lo que la protagonista siente su propia incertidumbre ante una decisión vital:

\author{
Desde el fondo del mar \\ estás llamando. \\ Yo me alejo de lo azul \\ mas me persigue \\ el sonido \\ el sonido \\ me persigue
}

No quiero vivir entre las olas

No quiero caminar en los alientos

de esta niebla salada que es un vértigo

El sonido

El sonido

me persigue

en laberintos que son sangre de pájaros

muertos por la luz de su mudez

Mas no quiero lanzarme hacia el abismo

y me hipnotiza el canto

los cuerpos de la danza

la preñez de la sal

Los hijos peces me están llorando

Han destruido el arco-iris 
Me tapo los oídos frente al mar (Miranda 2011,33-34)

La decisión vital que se manifiesta, se entroniza dentro del texto como lugar fronterizo, como una textualidad de la contradicción en la subjetividad de la sujeto, la que se siente a la vez seducida y asustada ante un trayecto experiencial que la podría arrancar de una aparente estabilidad ${ }^{12}$. Frente a tal incertidumbre, la voz enunciativa escoge el goce del "cuerpo [en el] cuerpo", es decir, la experiencia colectiva en la experiencia de los cuerpos es la que le abre el trayecto a su transformación y la que de igual forma, será su suicidio, su cuerpo que se diluye. Esta articulación vital y fatal en la sujeto, ya es conocida por ella a través de la sabiduría que le entrega su delirante visión, es más, nos atrevemos a decir, que conforma el tejido mismo de su saber delirante. Leamos entonces, el camino que realiza la sujeto desde que materializa su decisión:

Un camino se abre en el medio del mar.

Tú estás al otro lado.

Intuyo los alientos y el oleaje que hay en ti

es el mismo en el cual se sumergen las sirenas y los peces.

Los cantos se suceden en mi lengua.

Gaviotas que devoran mi vestido.

Estoy aquí mirando las luces de tu cuerpo.

Yo siempre estoy aquí.

Entro al mar algunas veces y regreso.

Un camino se abre en la mitad del cielo.

Atorarme de sal es mi deseo.

Llenarme de la espuma y del aceite marino

que te envuelve.

Muérdeme, te digo.

Muérdeme el descenso 


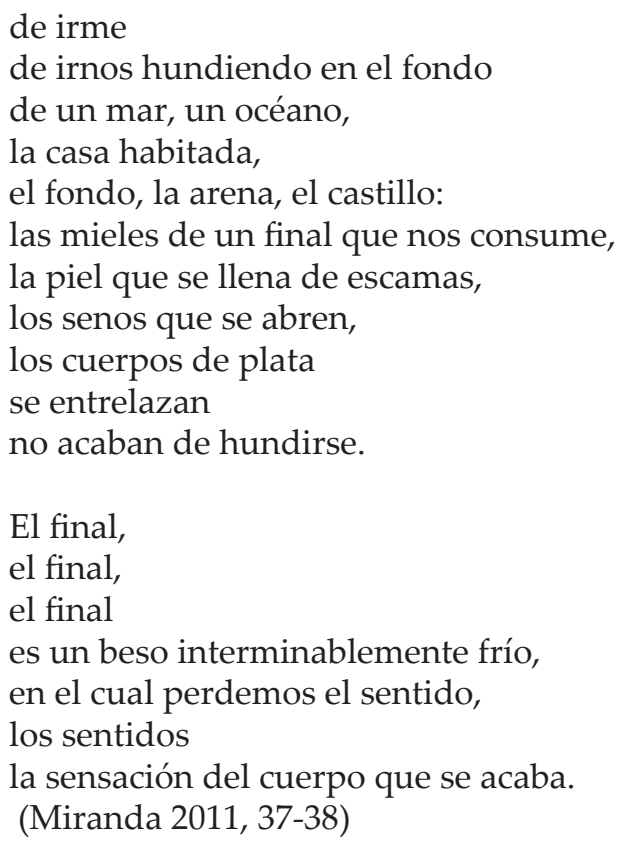

A partir de esta relación de distancia-cercanía, de ausencia y encuentro, el deseo de la amante se concreta por el deseo de la reunión con el otro como "fusión de y con un semejante" -que podría por un momento conducir a una relación que vuelve a convocar lo "incestuoso"-. Lo que entrelaza entonces a los personajes de los poemas, no es precisamente la erótica normativa de la diferencia, sino que de la "similitud".

La sujeto al reunirse con Shumpall adquiere un cuerpo diferente, es decir, se materializa la transformación corporal. Dicho de otro modo, la reunión erótica impulsa una modificación que, a la vez, contiene todas las transformaciones anteriores de la sujeto, incluyendo su disolución (a modo de un rizoma corporal, si se quiere). Por lo tanto, se trataría también de una alteración en el conocimiento de la sujeto, respecto a sí misma. La corporalidad que nos señala Roxana Miranda se halla en la frontera discursiva que representa la carne corporal y el cuerpo "sobrenatural" que habita en el mar y que muchas veces es el mar mismo, como simbólicas de un "diformismo" respecto a cualquier calce social y cultural en relación a lo predeterminado como "normal", incluso dentro de la "realidad" po- 
sible que se narra en el relato oral al que se alude en el texto ${ }^{13}$. O sea, estamos frente a un cuerpo que se ha modificado a través de variadas políticas de autoproducción de subjetividad, hasta convertirse en un espacio dialógico en la autoinscripción de las experiencias. La sinuosidad de un cuerpo-pez ${ }^{14}$, es la figura que simboliza esta revolución o ambigüedad corporal, un cuerpo "híbrido" que se despliega como diferenciación, como una contravención cultural. Si es así, estamos frente a una carnavalización del cuerpo erótico, puesto que esta metáfora de la "diformidad" sexual de la "hembra" se puede asociar a cierto saber o saberes de la sujeto de los poemas que contravienen la normativa, tanto del relato oral como de las construcciones sociales, para manifestarse como cuerpo "extraoficial". En este sentido, nos referimos entonces, a la subversión de la metáfora [y por lo tanto] a la subversión de aquellas dimensiones que forman parte de las metáforas: acciones corporales, experiencias corporales y usos del lenguaje (Zilbeti s/f). Respecto a esta última perspectiva, el uso del lenguaje en el texto que revisamos, se convierte en el transmisor del deseo, en la comunicación con la que se abren las imágenes que entregan de manera constante diferentes planos de la alteridad. El cuerpo opera a través del proceso corporal de decir, de comunicar. Todo lo que se manifiesta en el lenguaje de los poemas, no solo circula a través de la materialidad física de la sujeto, si no que restablece una revelación del cuerpo mismo (Butler 2006).

En este universo simbólico, la transformación corpórea de la sujeto corresponde por una parte, a una transversalidad de género y por otra, a la producción de un saber o de una serie de saberes interconectados, al mismo tiempo, con una singular perspectiva de las relaciones amorosas ${ }^{15} \mathrm{o}$, si se prefiere, con una percepción de la diferencia de la erótica entre los cuerpos que tienen que ver con la fusión erótica entre semejantes. Por lo tanto, la sujeto se posiciona en la "complejidad de la multiplicidad" que le da el asumir una relación entre sujetos creada a partir del conocimiento de su propia singularidad, distanciándose del maniqueísmo dicotómico del género y el sexo. Estos espacios de una corpográfica de la fusión, de la transformación y de la disolución, los podemos comprender desde una óptica política (reivindicativa) como territorios fronterizos que se sitúan como lugares de reciprocidad y flujo permanente, fuera de cualquier custodia y clausura en el trayecto de la experiencia. 
Finalmente, la sujeto de los poemas emplaza la ruptura de los cuerpos como una manifestación "real" dentro de las posibilidades que otorga la autoproducción de experiencia y como estrategia vital, en el sentido de una experiencia que se configura en una visión de mundo que se hace y se transforma en un proceso cíclico. Proceso que termina, para inaugurarse, en la muerte de la sujeto. La muerte como lugar de la lucidez y del delirio (también como lucidez), será el espacio desde el cual la voz que enuncia narrará su historia de identificaciones eróticas, mestizas y de planos intercomunicados que posibilitan la resignificación o relectura de un relato original, quizás de manera más precisa, del cuerpo de una narración tradicional mapuche. La muerte como proceso de conocimiento, de saberes que posicionan a la sujeto en una interfaz de la tragedia, es decir, la sujeto se encuentra en la imposibilidad, finalmente, de la continuidad de los desplazamientos en y de la cultura. Sin embargo, es la tragedia de la muerte la única que puede dar cuenta de la erótica singular que construyen los cuerpos del poemario:

Cuando despareciste un agujero se abrió en el centro de mi pecho.

Primero fue el oleaje lo que vi salírseme a la arena.

Después fueron los peces y ballenas con sus gritos y sus algas de vestido.

Yo trataba de taparme con puñados de sal toda la huída.

Mas mi mar miraba al mar y a la ausencia del espejo mas mis conchas, caracolas se me huían a enterrárseme en la niebla.

Después vino una tormenta.

Después vino una tormenta.

Un derrame de las lágrimas revolcándose en la orilla.

Nunca supe de la ausencia sólo hasta que vi vertidas frente a mí mis propias aguas. (Miranda 2011,41)

Es la experiencia de la muerte, de la ruptura, de la ausencia la que 
se vivifica en el saber de la sujeto. La estructura dialógica del texto se mantiene hasta el final, puesto que la tragedia de la sujeto es la fuerza renovadora en la apropiación de una erótica como elemento poderoso en la transformación de la voz enunciativa. Es el proceso de alteridad que emerge desde esta tensión amor-muerte -nunca resuelta- entre, por un lado, la necesidad política de configurar identificaciones relacionales y situacionales con otro cuerpo deseado, que al mismo tiempo configurará su propia experiencia de identidades, y por otro, el juego plural de las diferencias, que son más bien semejanzas y que se valen de las ambigüedades en la voz (enunciación) y en el depósito corporal que porta esa voz. Ni lo erótico (donde actúan el cuerpo, las sexualidades y los géneros), ni la muerte, ni, incluso, el relato oral son proyectados aquí como dimensiones predeterminadas ${ }^{16}$, sino como tácticas de enunciación y puntos de vista que deconstruyen valores y renuevan significados en torno a las constelaciones ambiguas de la experiencia, la subjetividad y de la alteridad como contenidos de conocimiento en el proceso de identificaciones. Es así como el texto de Roxana Miranda se va configurando como una espiral de cortes y de interrupciones, incluso cuando va construyendo diferentes desarticulaciones entre la historia de shumpall, que nos trae la autora y el relato original respecto a la relación de los amantes.

Primero, y como escenario en el cual se desenvuelven todas las demás rupturas, se encuentra la relación erotizada y tanatizada entre la shumpall (sujeto de los poemas) y el niño-pez; en este sentido, en el epew tradicional, la relación se manifiesta como una reproducción cultural del "matrimonio" entre un hombre y una mujer ${ }^{17}$. Segundo, en el poemario de Rupailaf, la mujer siempre desea ser "raptada" por el dueño de las aguas, en cambio en la narración tradicional, la joven desconoce esta situación. Es decir, en el relato de Miranda y en palabras de Kristeva, se produce un "traslado de sentido" porque "el sujeto y el objeto de la enunciación [han confundido] sus fronteras" (Kristeva 1987, 236). Y finalmente, la relación de los amantes, en el texto de la autora, se construye como una tragedia erotizada, en cuanto la ausencia o la muerte toman lugar a través de la metáfora de la "no videncia". Es justamente, en el pliegue de esta metáfora donde se sitúa la historia del poemario, puesto que por un lado, la sujeto decide no ver, no tener conciencia del mundo y de su amante 
y por otro lado, y al mismo tiempo, esta representación de un estado de "ceguera", es la videncia y el delirio amoroso de la sujeto. Por lo que se comprende que el final "feliz" programado culturalmente como un continuum trascendental y que se presenta en el epew de Shumapll, en Roxana Miranda se problematiza a través de la tragedia del desencuentro de los amantes, que ya ha sido comentado más arriba.

\section{Conclusiones aproximadas}

La escritura aquí explorada, despliega la tarea crítica de desorganizar y reinventar los signos de las culturas (occidental y mapuche) desde un punto de vista no hegemónico, ni tradicionalista en el caso mapuche. El proyecto escritural que hasta ahora nos ha entregado la autora, nos enfrenta hoy a una doble responsabilidad. Por una parte, contravenir el dispositivo sociocultural mascultista y "cosmovisonista" que fundamentalmente organiza la diferencia en desigualdad genérico-sexual. Por otra parte, desocultar los artificios a través de los cuales el mismo dispositivo anterior, presenta la representación textual de "lo femenino" como compostura ligada a existencias prefiguradas y destinadas, además de utilizar la metáfora de la diferencia para destacar esencialismos, victimizaciones y subordinaciones. El poemario revisado -y de manera semejante a los dos libros anteriores de la autora-, posiciona sujetos en proceso que movilizan la filiación "mujer" hacia múltiples territorios de resignificación y problematización contextual, en lugar de dejarla atada a una identificación prefijada.

La poeta activa en su producción poética, tensiones y contradicciones que admiten desplazamientos y restauraciones de diferentes niveles textuales, fundamentalmente entre "mujeres", "género", "erótica", "identidad", "experiencia", "subjetividad", "etnicidad" y "representación", que le facilitan el desentrañamiento permanentemente de una "estrategia de multilocalización del sujeto [...], para 'desdibujar fronteras sin quemar puentes'"' (Richard 2008, 60) ${ }^{18}$. Esta posicionalidad múltiple de las sujetos, permite el empalme de lugares intermedios en los cuales un carnaval de representaciones y prácticas insubordinadas demandan un resquebrajamiento de cierta "veracidad" asignada a los cuerpos y a las identidades. Estos terri- 
torios fronterizos, atiborrados de mesticidades, se arman y rearman a través de heteroglosias y de polivocalidades en el lenguaje y en los cuerpos portadores del lenguaje. Se trata de lugares en los cuales las subjetividades se desidentifican, porque en ellos confluyen la abyección, como diría Butler, es decir, lo no acabado, lo ambiguo, lo nómada, lo diforme; lo que intenta configurarse en la ruptura de los "universalismos" identitarios. La potencia desestabilizadora de estas ambigüedades, contradicciones y singularidades de significación, facultan a la sujeto de los poemas para removerse de las identificaciones identificables, valga la redundancia, y de esta forma, trastornarse de manera creativa entre la pertenencia y el desarraigo. Este vaivén de necesidades y deseos tiene la posibilidad de perturbar los preceptos oficiales, tanto occidental como mapuche, de los ideales identitarios contraídos en una "teatralización" de las mujeres -léase como significante unívoco-, que únicamente pretende una conformación "política" sin cortes ni excedencias, sin revueltas ni digresiones. La autora logra interrogar el fundamento identitario que instala la creencia de que las producciones de subjetivación se comprimen sin más, a previstos diseños de identidad, lo que genera la visibilización de cualquier signo fijo de reclutamiento de las identidades.

Una de las dimensiones más entroncadas que emerge, no solo en Shumpall sino que también en los otros libros de la poeta, en los tres libros indagados de la autora, es la ambigüedad del género y del sexo, la que alude hacia un "transformismo" de las identidades que carcome la binaria programación de la masculinidad y de la feminidad sistematizada. Mientras en ambas sociedades, occidental y mapuche, se fragua la sujeción a un "deber ser", en la escritura de Roxana Miranda el travestismo participa de lo indeterminado y variable en la experiencia de las sujetos, lo que provoca la desnaturalización de cualquier referente regulado. Por lo tanto, su producción poética hace intervenir una contorsión corporal y lingüística que carnavaliza, a través de la erótica y de la tragedia, la uniformidad de los cuerpos y de los géneros con el desenvolvimiento de un doblaje en la autoproducción de la sexualidad. De esta forma, el conflicto entre norma (normalidad-legitimidad) y contravención (alteridad-abyección), desenvuelve formas siempre fronterizas, cruzadas y censuradas. 


\section{Notas}

1. Este libro fue financiado con el aporte del Fondo de Actividades Culturales Regionales de Los Lagos y el Consejo Nacional de la Cultura y las Artes. Línea Becas de Creación Literaria del Fondo del Libro y publicado por Del Aire Editores.

2. Una dinámica similar sucede entre Las tentaciones de Eva (2003), su primer libro y Pu llimeñ ñi rulpázuamelkaken. Seducción de los venenos (2008), su segundo libro.

3. En este sentido que nos presenta el poema, podemos pensar también en la imagen de la Pincoya que a diferencia de la mujer-pez, su cuerpo es completamente humano. La Pincoya sale de las profundidades del mar con un traje de algas que cubre solo una porción de su cuerpo.

4. Con la noción de "tercer espacio", me refiero especialmente, a un espacio que ha desplazado las construcciones de una lógica binaria respecto a los sujetos y sus procesos de subjetivación e identitarios. Por lo que este concepto alude a un espacio abierto, múltiple y de localización intermedia, es decir en directa relación con la configuración fronteriza de la experiencia. Al respecto es fundamental considerar lo planteado por Homi Bhabha en relación al "tercer espacio": “...espacio indeterminado de los sujeto(s) de la enunciación. Es este el tercer espacio, aunque irrepresentable en sí mismo, constituye las discusiones discursivas de enunciación que aseguran que el sentido y los símbolos de la cultura no tienen unidad o fijeza primordial; que incluso los mismos signos pueden ser apropiados, traducidos, rehistorizados y leídos de nuevo" (Bhabha, 2002: 58).

5. Es interesante cómo el texto de Roxana Miranda mantiene guiños implícitos con cierta producción mistraliana, especialmente con Desolación (1922), puesto que en este último, se desarrolla a largo de los poemas el encuentro con el amado que al mismo tiempo, es una alianza enajenada y un encuentro presagiado, imposible de eludir. Libro en el que también se hacen presente los deseos de la sujeto enamorada, los que aparecen continuamente en tensión con las ansias y la angustia frente a la muerte del niño-amante.

6. La autora argumenta que el proceso de "retradicionalización" se constituye actualmente dentro de las producciones estéticas mapuche como una herramienta fundamental de contradiscurso, como es el caso de Adriana Paredes. Sin embargo, habría que decir que la poética de Roxana Miranda no ha sido recogida como parte de este proceso hasta el momento (García 46).

7. José Ancán argumenta, desde un frontis de disidencia, que el discurso "cosmovisionista" que ya tiene varias décadas funcionando dentro de los discursos públicos -y yo diría, también poéticos- mapuche; “intenta desentrañar los aspectos más profundos y refinados de su sistema cultural [mapuche], y las maneras cómo esa cultura entiende y organiza su visión de las cosas materiales e inmateriales que la rodean [...]. El 'cosmovisionismo' se convierte así en una especie de 'ojo mágico' que por encima de tiempos y distancias, todo lo ve y todo lo comprende. [...]. Si bien en primera instancia se asume en los textos 'cosmovisionistas' la condición histórica de la pérdida de la cultura y las tierras a manos de los winkas, españoles primero y chilenos después, esta constatación va perdiendo peso paulatinamente hasta derivar en aspectos esencialmente 'espirituales', donde son los propios mapuche los responsables tanto de las pérdidas como de la recuperación de la 'espiritualidad. [...]. De esta forma, la sociedad propia es visualizada en términos de victimización y autoexaltación [...]. El 'cosmovisionismo' asigna a la mujer prácticamente, todo el 
peso y la responsabilidad de la cultura: madre, esposa, educadora y trasmisora de la cultura, chamana, artista, etc. El roce entre los discursos del relativismo y el de los derechos humanos universales aquí se manifiesta en toda su anchura" (Ancán, 121,129 y 131).

8. Que la familia original mapuche esté compuesta de cuatro elementos no es arbitrario, puesto que la configuración diálogica del número cuatro es significativa entre los mapuche, ya que representa un espacio de "perfección", un territorio que se completa y que está en directa relación con la percepción que ellos tienen de la conformación del mundo: Meli Wixan Mapu, los cuatro puntos de la tierra. Ya en los estudios de Rodolfo Lenz a fines del siglo XIX, se señala la importancia que esta cifra tiene para la conformación de mundo mapuche. Ver Lenz, R (1895-1897). Estudios Araucanos. Santiago: Imprenta Cervantes, 12 y 427.

9. Nótese aquí la influencia de un imaginario occidental en el relato.

10. En el sentido de esta "naturalización" del sexo y el género, Judith Butler coteja la relación de sexo-género con la que existe entre "naturalización" y contrato social, desde donde Butler concluye que la "naturalización" es una "ficción" fabricada por el mismo contrato social para instaurar las condiciones propicias a la construcción normativa del género. Ver Butler 2002.

11. La conformación del tiempo en el libro de Roxana Miranda, comprende una multiplicidad de desplazamientos temporales. Es decir, la dinámica temporal se moviliza, por una parte, como un espejeo respecto a la configuración de sujeto plural que aparece en el texto, es decir, la temporalidad se construye en el cruce de una alteración temporal con una sincronía que posibilita que la sujeto se encuentre, al mismo tiempo, en alternancia entre futuro y presente; este último, muchas veces, situado en el pasado (la memoria, la visión). Por otra parte, un tercer elemento constitutivo de la temporalidad estética del libro, lo constituye, de manera angular, el tiempo de la naturaleza. Este último, por cierto, cíclico, señala implícita y fundamentalmente las transformaciones, los encuentros y las rupturas en el devenir de los personajes. Así mismo, permite el acceso a la muerte de la sujeto como posicionamiento de un delirio que al mismo tiempo es conocimiento. En síntesis, es principalmente la simbólica del agua la que marca el movimiento temporal de la historia poética y el desenvolvimiento agitado, contradictorio y ambiguo de la voz enunciativa.

12. Una lectura, desde un punto de vista de referencia cultural mapuche en el marco de una construcción de sujeto mestiza, puede realizarse en cuanto la sujeto se encuentra frente a la incertidumbre de una pertenencia a la sociedad mapuche, simbolizada en la contradicción que experimenta frente a la posibilidad de reunirse con Shumpall ("Yo me alejo de lo azul/ más me persigue"), este último como una construcción cultural sobrenatural mapuche de alta referencialidad. Así mismo, en este poema, como en otros, se hace referencia a que la sujeto habita fuera del mar por lo que supone una relación más o menos directa con el epew de Shumpall, pues se trataría de la mujer (joven-niña) que es raptada por el "dueño" de las aguas.

13. No olvidemos que en la narración oral de Shumpall, el encuentro entre la mujer y el shumpall, siempre mantiene los patrones culturales de la heterosexualidad separada. La mujer se (o es) transformada en otro shumpall que se diferencia tanto corporalmente (sexo) de su "marido", como en los roles que desempeña.

14. Algunas de las transformaciones que se encuentran en el texto, corresponden a 
la de mujer a una shumpall, que también es la Pincoya y probablemente también sea la hermana de esta última: la mujer pez.

15. Lo mismo se puede afirmar respecto a la resignificación que se hace de la relación de amor entre los personajes en el epew de Shumpall.

16. En relación al relato oral que cruza todo el texto, debemos decir por una parte, que se trata de un cruce de relatos que convergen para construir la historia del texto. Si bien, en apariencia predomina la narración de Shumpall, también forma parte de esta multiplicidad discursiva, "La Pincoya", su hermana "La mujer-pez", "Mankián" y el "Caleuche", posiblemente entre otros. Quizás la pertinencia de un estudio ligado a la cosmovisión mapuche, especialmente huilliche, podría dar cuenta de manera más exhaustiva de estos niveles estéticos. Por lo pronto, no es materia de profundización en este artículo.

17. La mujer se va a vivir a las profundidades del mar o lago con Shumpall, convirtiéndose en una shumpall. Ambos tienen un hijo (un niño-lobo o niño-pez). Esta unión "matrimonial" tiene como consecuencia el desequilibrio de la sociedad mapuche, debido a su configuración cosmogónica dual del mundo. Es por esto, que Shumpall (marido), debe retribuir con alimentos marinos o la buenaventura de una exitosa pesca, a la familia de la "novia". Esta última situación se solía hacer antiguamente: el hombre debía "pagar" por llevarse a la mujer a vivir con él.

18. El subrayado pertenece al original.

\section{Bibliografía}

Ancán, José. “'Negritud' y 'cosmovisionismo' mapuche frente al poder neocolonial. Apuntes preliminares para una reflexión (auto) crítica". En Elena Oliva y otras (eds.). Aimé Césaire desde América Latina. Diálogos con el poeta de la negritud. Santiago: Ediciones Facultad de Filosofía y Humanidades, Universidad de Chile, 113-136, 2011.

Arellano Hermosilla, Claudia. "Roxana Miranda Rupailaf: 'soy una mezcla de todas las cosas'”. Suralidad, s/p, 2009 (Disponible en http://suralidad.blogspot.com/2009/01/roxana-miranda-rupailaf-soy-una-mezcla.html).

Butler, Judith. Cuerpos que importan. Sobre los limites materiales y discursivos del sexo. Barcelona: Paidós, 2002.

. Deshacer el género. Barcelona: Paidós, 2006.

Carrasco, Hugo. El viaje al otro mundo en la gramática mítica mapuche. Nueva Stylo [versión electrónica], 2, 2534, 1999.

Disponible en http://repositoriodigital.uct.cl:8080/xmlui/handle/123456789/178

García, Mabel. “La construcción del relato mítico ancestral en el arte y la poesía mapuche actual" [versión electrónica]. Papeles de Trabajo, 20, 43-56, 2010.

Disponible en http://www.scielo.org.ar/pdf/paptra/n20/n20a05.pdf

Huirimilla, Paulo. "Roxana Miranda Rupailaf: lo propio y lo ajeno". Letras.s5.cl, 2009 (Disponible en http://letras.s5.com/jh160509.html).

Kristeva, Julia. Historias de amor. México: Siglo XXI Editores, 1987.

Lenz, Rodolfo. Estudios Araucanos. Santiago: Imprenta Cervantes, 1895-1897.

Miranda Rupailaf, Roxana. Las tentaciones de Eva. Región de Los Lagos: Secretaría Regional Ministerial de Educación, 2003. 
. Pu llimeñ ñi rulpázuamelkaken. Seducción de los venenos. Santiago: Lom Ediciones, 2008.

. Shumpall. Región de Los Lagos: Del Aire Editores, 2011.

Moraga-García, Fernanda. "Adriana Pinda y el habla escrita de la ajenidad: 'Relámpago"'. Alpha, 23, 117-136, 2006.

Richard, Nelly. Feminismo, género y diferencia(s). Santiago: Palinodia, 2008.

Rubin, Gayle. "El tráfico de mujeres: Notas sobre la 'economía política' del sexo". Revista Nueva Antropología, año/vol. VIII, 30, 95-145, 1986.

Zilbeti, Maider. "Corporalización: nuevos feminismos y actantes políticos".

Disponible en www.disisex.org/.../corporalizacion-nuevos-feminismos-y-actantespoliticos.pdf 